\title{
Surface pollen assemblages of human-disturbed vegetation and their relationship with vegetation and climate in Northeast China
}

\author{
LI ManYue, LI YueCong ${ }^{*}$, XU QingHai, PANG RuiMing, DING Wei, \\ ZHANG ShengRui \& HE ZhiGuo
}

College of Resources and Environment and Hebei Key Laboratory of Environmental Change and Ecological Construction, Hebei Normal University, Shijiazhuang 050024, China

Received June 4, 2011; accepted September 30, 2011; published online November 19, 2011

\begin{abstract}
Pollen assemblages of 53 surface pollen samples from farmlands and wastelands in Northeast China were analyzed. Tree pollen percentages were usually higher than 30\%, with Pinus (26.9\%), Quercus $(0.9 \%)$, Betula $(0.9 \%)$ and Populus $(0.7 \%)$ as the major types, and herb pollen percentages were usually higher than 50\%, with weedy Poaceae (8.7\%), Chenopodiaceae (7.1\%), Artemisia (1.9\%) and Compositae (3.5\%) as the major taxa. Thus, the pollen assemblages were consistent with the regional vegetation compositions. However, there were differences in pollen assemblages among regions, especially among different geomorphological units. For example, in the mountains, there were more types of tree pollen and higher total percentages (average 42\%) than in other areas, while cereal pollen percentages were lowest (11.2\%). In the hills and high plains, herbs made up more than $60 \%$ of the pollens, with cereals (average 53.6\%) the dominant type. In the low plains, pollen types were similar to those in the hills and high plains, but total pollen concentrations and the proportion of Concentricystes were much higher, while cereal pollen percentages were slightly lower (average 41.6\%). Pollen assemblages in different land use types also differed. For example, in farmland, cereal pollen percentages were more than $40 \%$ and Chenopodiaceae was usually less than $2.5 \%$, while in wasteland, weedy Poaceae was usually less than $10 \%$ and Chenopodiaceae was usually higher than $25 \%$. Total pollen concentrations in farmland (average 3909 grains $/ \mathrm{g}$ ) were much lower than in wasteland (average 15074 grains/g). Redundancy analysis revealed that pollen assemblages were significantly negatively correlated with mean annual temperature $(-0.73)$ and July mean temperature $(-0.81)$ and significantly positively correlated with mean annual precipitation (0.48), indicating that pollen assemblages in the artificial or human-disturbed vegetation reflect regional climate well.

Comparison of pollen assemblages in different areas of northern China showed that pollen concentrations reflect the intensities of human impact to some degree. For example, pollen concentrations decrease as human impacts increase in intensity. The cereal pollen proportions in farmland differed by area. In Northeast China, cereal pollen proportions were distinctly higher than in most other areas of northern China, suggesting differences in planting habits and climate.
\end{abstract}

Northeast China, farmlands, wastelands, pollen assemblages, human impact, climate

Citation: $\quad \mathrm{Li} \mathrm{M} \mathrm{Y,} \mathrm{Li} \mathrm{Y} \mathrm{C,} \mathrm{Xu} \mathrm{Q} \mathrm{H,} \mathrm{et} \mathrm{al.} \mathrm{Surface} \mathrm{pollen} \mathrm{assemblages} \mathrm{of} \mathrm{human-disturbed} \mathrm{vegetation} \mathrm{and} \mathrm{their} \mathrm{relationship} \mathrm{with} \mathrm{vegetation} \mathrm{and} \mathrm{climate} \mathrm{in} \mathrm{Northeast}$ China. Chin Sci Bull, 2012, 57: 535-547, doi: 10.1007/s11434-011-4853-9

Pollen is an important proxy for past environment change. Modern pollen assemblages, and their relationships to vegetation and climate, are essential to the reconstruction of paleoenvironments [1-7]. Research in recent years has shown that human impacts are not only driving current and future environmental changes, but have also played signifi-

*Corresponding author (email: lyczh@yahoo.cn) cant roles in environmental changes over the past 8000 years [8-10]. Palynologists are becoming increasingly interested in the pollen assemblages of human-disturbed or -impacted vegetation types, so as to better recognize past human impacts and to predict future environmental changes. For example, Court-Picon identified pollen types that could indicate different artificial vegetation types by comparing modern surface pollen assemblages in natural and artificial 
vegetation in the French Alps [11,12]. Based on grass pollens in the French Pyrenees, Buttler et al. argued that pollen assemblages reflect differences in vegetation caused by differing intensities of human activities [13]. Liu [14] studied the pollen assemblages of different vegetation types in the steppes of East Asia and concluded that changes in the proportions of Chenopodiaceae pollen within a steppe type reflected the degree of interference by human activities.

Within China, studies of pollen assemblages in different regions and different types of farmland have provided insight into past human activities [15,16]. Pang et al. [17] thought that farmland pollen assemblages reflected regional vegetation characters and that variations in the proportions of pollen among agricultural units were mainly due to the intensity of human impact or to different planting habits. Ding et al. [18] found that the assemblages and spatial distributions of major pollen taxa could reflect the impact of human activities and changes in the natural environment in the warm temperate hilly areas of eastern China. Nevertheless, compared with the study of natural vegetation, research on pollen assemblages in artificial or human-disturbed vegetation types is still insufficient and has been focused on only a few geographic regions.

Northeast China is one of the cradles of Chinese civilization. Six thousand years ago, humans began to live and multiply in this area, thus creating the Northeastern Neolithic Xinkailiu Culture [19]. In modern times, large-scale reclamation has resulted in artificial and human-disturbed vegetation types being the most important, but there are no reports on modern pollen assemblages. We analyzed 53 modern surface pollen samples from farmlands and wastelands with different terrains and different intensities of human impact. We correlated these pollen assemblages to local vegetation and regional climate to provide basic scientific data with which to better recognize human activities in the Holocene and to predict future environmental changes in Northeast China.

\section{Study area}

The study area is located at $\mathrm{N} 40^{\circ} 02^{\prime}-49^{\circ} 14^{\prime}$, E $119^{\circ} 50^{\prime}$ $125^{\circ} 10^{\prime}$, including Liaohe Plain, Songnen Plain, and Daxinganling Mountains. The locations of sampling sites are shown in Figure 1. The study area has a temperate continental monsoon climate (ranging from warm temperate in the south to mid-temperate in the north), with local conditions influenced by latitude, distance from the sea, topography, and other factors. The elevation ranges from 2 to 931 $\mathrm{m}$ in the study area. Average annual temperatures vary from -1.5 to $8.1^{\circ} \mathrm{C}$ and annual precipitation from 350 to $700 \mathrm{~mm}$. Rainfall mainly occurs in July and August [20-23].

The natural vegetation in the study area includes temperate coniferous and broad-leaved mixed forests, temperate deciduous forests, and warm temperate deciduous broadleaved forest. Vegetation composition changes with elevation [21-23]. In the low plains below $200 \mathrm{~m}$ a.s.l., farmland dominated the landscape. The natural vegetation was very

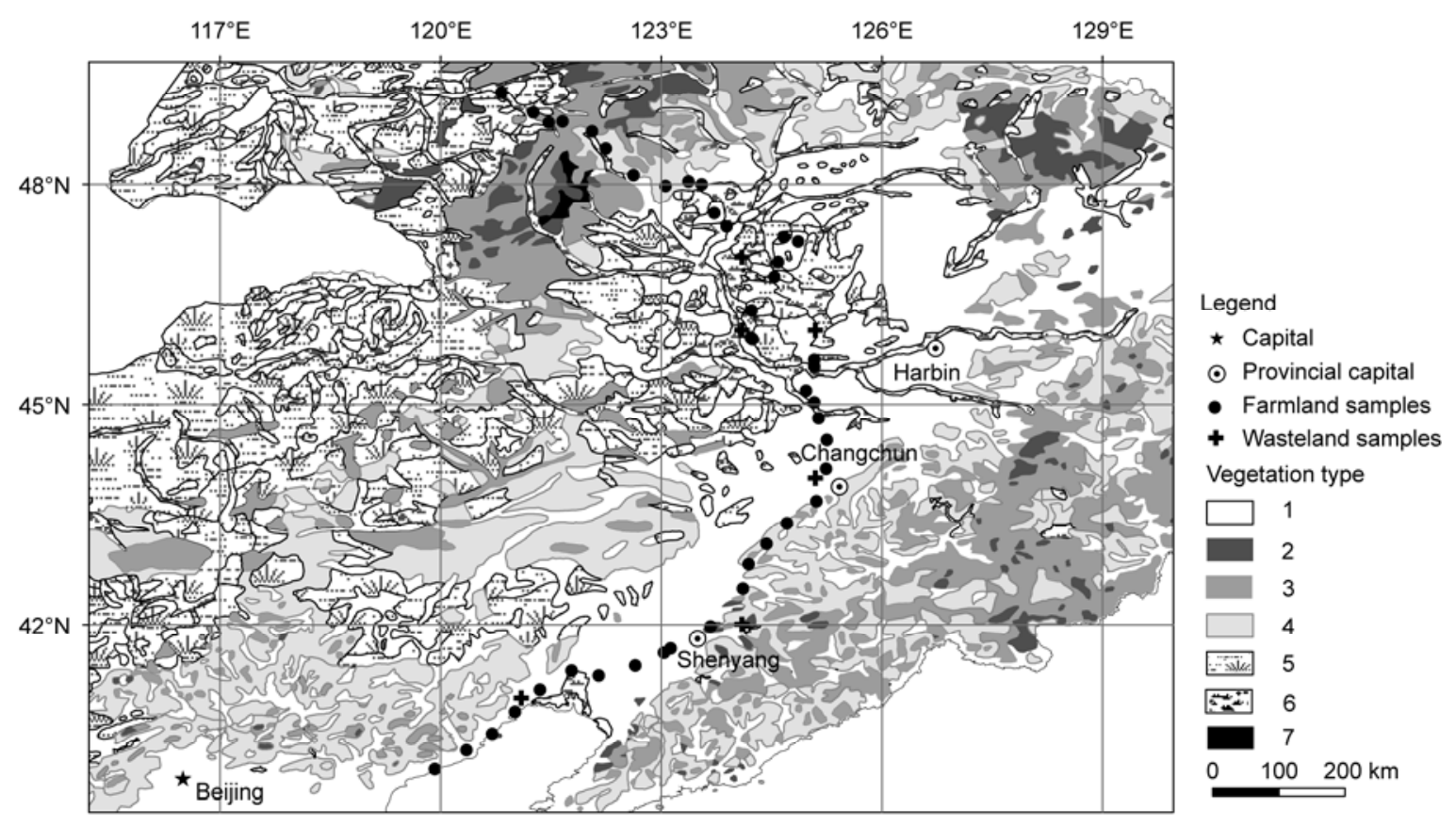

Figure 1 The vegetation types in the study area and the locations of sampling sites. Vegetation type: 1, Farmland; 2, boreal temperate mountain deciduous needle-leaf forest; 3, warm temperate deciduous broad-leaved forest; 4 , temperate deciduous shrubland; 5 , temperate steppe; 6 , temperate meadow; 7 , lakes, swamps. 
rare, consisting of scattered trees of Pinus tabuliformis, Quercus liaotungensis, Q. mongolica and so on. In recent years, the areas planted with $P$. tabuliformis and Robinia pseudoacacia have increased substantially. Populus, Ulmus, Salix, Sophora japonica and other species were scattered along roadsides and in cities and villages.

In the hills and high plains from 200 to $500 \mathrm{~m}$ a.s.l., farmland was still abundant and natural vegetation has been seriously degraded. On south-facing slopes, natural forests were usually dominated by $Q$. liaotungensis and $Q$. mongolica, and mixed with $P$. tabuliformis and small numbers of $Q$. acutissma, $Q$. dentata, Fraxinus rhynchophylla, and other species. Lespedeza bicolor and Zizyphus sativa mostly represent the understory shrubs. On south-facing slopes, shaws and shrubs were often mixed together. The most common trees were Betula dahurica, Ulmus japonica, and Acer mono. Corylus heterophylla and Spiraea spp. were common shrubs, while. Stipa grandis, Leymus chinensis, Cleistogenes squarrosa and Potentilla dominated the herbs [22,23].

Farmland was rare in the Daxinganling Mountains between 500 and $900 \mathrm{~m}$ a.s.1., where more nature vegetation can be found. The dominant trees were Larix gmelinii, $P$. tabuliformis, Juniperus rigida, Quercus variabilis, $Q$. acutissma, Q. mongolica, Betula dahurica, and Platycladus orientalis. The most common understory shrubs were Rhododendron dauricum, Vitex spp., Jujube spp., and Stipa baicalensis [20,24].

Artificial vegetation consists mainly of farmland. The main crops include Zea mays, Triticum aestivum, Oryza glaberrima, Sorghum vulgare, Glycine max, Vigna radiata, and Arachis hypogaea. Common fruit trees include Malus spp. and Prunus persica, and common vegetable crops include Brassica oleracea, Lycopersicon esculentum, Capsicum frutescens, Raphanus sativus, and Solanum tuberosum.

The "wastelands" in this paper mainly refer to the abandoned crop and pasturelands where trees and shrubs are very rare and herbs predominate. The most common species were Vitex spp., Lespedeza bicolor, Artemisia spp., Typha orientalis, Chenopodiaceae, Cyperus rotundus, Xanthium sibiricum, Humulus japonicas, Sanguisorba officinalis, Helianthus annuus, Umbelliferae, Melissitus rutenica, Erodium stephanianum, and Amorpha fruticosa.

\section{Methods}

\subsection{Field work}

In total (Table 1), 53 surface soil samples were collected in June 2008. Samples included 44 from farmland (21 corn fields, 4 rice fields, 2 wheat field, 1 sorghum field, 3 orchards, 6 vegetable fields, 7 mixed crop fields) and nine wastelands. Samples were usually collected from the upper centimeter of soil, and every sample was a mixture of 4-5 points within a $9 \times 9 \mathrm{~m}^{2}$ sampling plot. Major plant taxa and community composition were recorded and the location (latitude, longitude, and elevation) of each plot was measured by GPS.

\subsection{Pollen analysis}

For each sample, $10 \mathrm{~g}$ of soil (dry weight) was prepared for pollen analysis. Pollen was extracted by treatment with a modified HCl-NaOH-HF method [25]. A tablet of Lycopodium (containing $27637 \pm 563$ spores) was added as a tracer to each sample. Pollen was identified and counted with a BX-51 Olympus light microscope (made in Japan) at 400x magnification. For each sample, at least 3-4 slides were checked, and more than 400 pollen grains were counted (excluding Concentricystes). Concentricystes were not included in the total pollen sums, rather we recorded the proportion of Concentricystes to total pollen. In keeping with previous studies, Poaceae were sorted into three pollen types based on size, diameter of the circular pore, and ornamentation [26,27] as follows: Grass pollen grains larger than $75 \mu \mathrm{m}$ with morphology and shape similar to modern corn pollen were identified as Zea mays pollen. Pollen grains that were $35-50 \mu \mathrm{m}$ (usually similar in shape and size) with distinct ornamentation and circular pores were considered to be cereal Poaceae (mostly wheat or rice pollen). Pollen grains smaller than $35 \mu \mathrm{m}$ with thinner walls and different sizes and shapes were identified as weedy Poaceae.

\subsection{Data processing}

The pollen percentages and pollen concentrations were processed with Excel 2003 software (manufactured by Microsoft Corporation), and pollen diagrams were drawn with Tilia software (manufactured by Eric. C. Grimm). The spatial distribution of sampling sites was evaluated with ArcGIS software (manufactured by ESRI, Inc, Arcmap version 9.3).

To investigate similarities and differences among pollen assemblages from different sites, clustering analysis (CA) was performed on the pollen data using MVSP software (manufactured by Kovach Computing Services). CA is a multivariate statistical analysis that is commonly-used in paleontology and palynology. Clustering analysis quantitatively determines the similarities among samples and then groups the samples into a classification tree [28].

Principal component analysis (PCA) can effectively distinguish the main pollen types [29]. We used redundancy analysis (RDA) to further investigate the relationships among vegetation, pollen assemblages and environmental conditions. PCA and RDA were performed using CANOCO version 4.5 (manufactured by Biometris-Plant Research International) [30,31].

Meteorological data were taken from China Meteorological Statistical Annals (supplied by China National Weather Service) and averaged for the 30-year period from 1961 to 
Table 1 Location and vegetation composition of the sampling sites in Northeast China

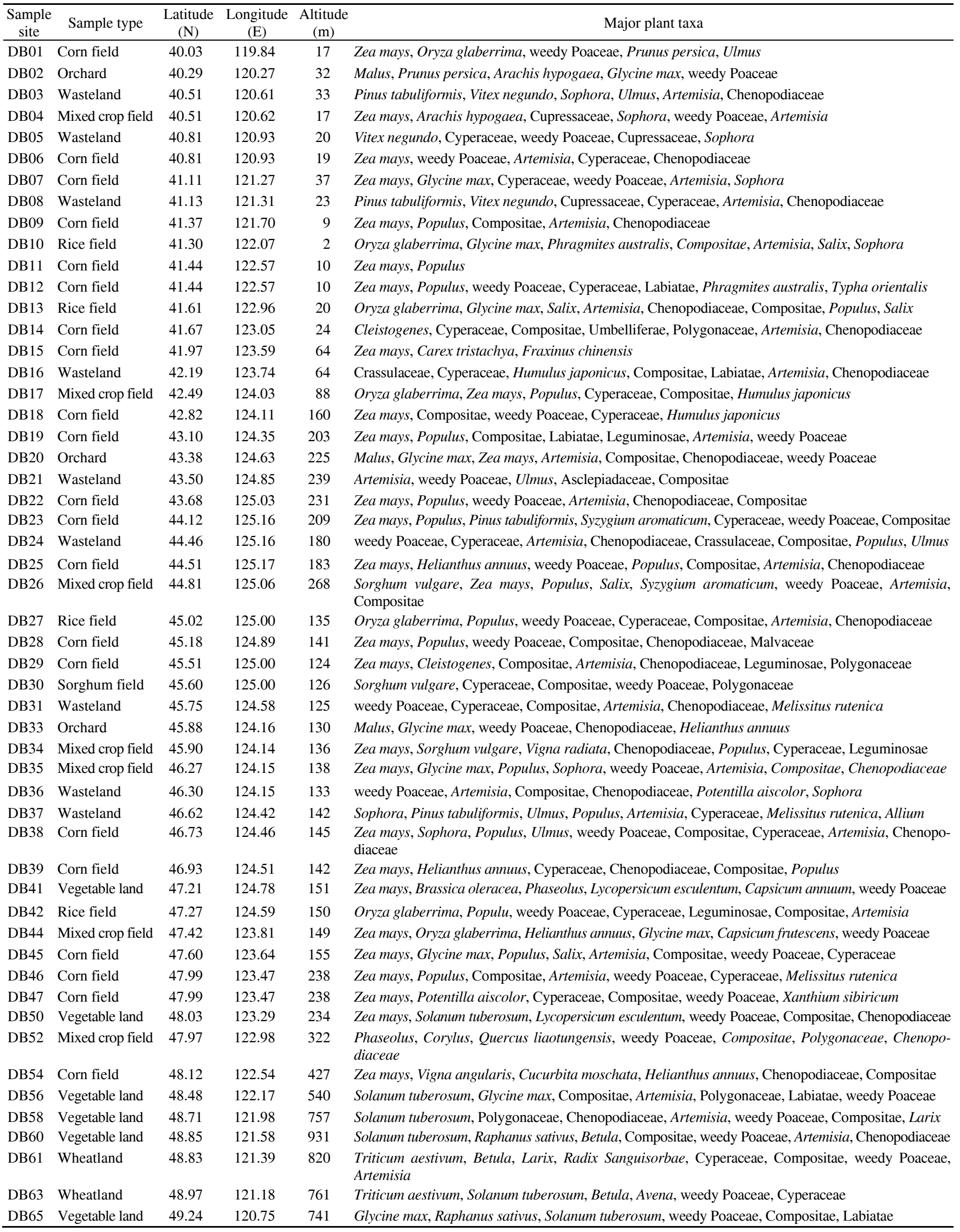


1990. The mean annual precipitation (MAP), the mean annual temperature $\left(T_{\mathrm{a}}\right)$, and the mean temperature of the warmest month $\left(T_{\mathrm{w}}\right)$ for each sampling site were calculated by the parabolic interpolation using the inverse square distance as the weighting factor with the Polation 1.0 program $^{1)}$, and the altitudinal temperature gradient was corrected using the universal temperature lapse rate of $0.60^{\circ} \mathrm{C} /$ $100 \mathrm{~m}$.

\section{Results}

A total of 55 pollen types and four fern spore types were identified from 53 samples. Twenty tree pollen types were recorded, with an average of $31.5 \%$ of total pollen and a maximum of $71.5 \%$. Tree pollen was dominated by Pinus (26.9\%), Larix (1.5\%), Quercus (0.9\%) and Betula (0.9\%). Populus, Ulmus, Tilia, Fraxinus, Anacardiaceae and Salix were common but with lower percentages. Five shrubs were identified with percentages less than $1 \%$. Elaeagnaceae and Rosaceae were common. Thirty herbaceous pollen types were identified. They constituted an average of $59.7 \%$ of total pollen, with a maximum of $95.6 \%$. Common types include Poaceae (cereals, 34.4\%; weeds 8.7\%), Compositae (3.5\%), Artemisia (1.9\%), Chenopodiaceae (7.1\%), Polygonaceae $(0.4 \%)$, Cyperaceae $(1.4 \%)$, Typhaceae $(0.5 \%)$, Humulus, Urticaceae, Ranunculaceae and Cruciferae. The average percentage of four fern spore types was $8.6 \%$, and the maximum was $40.4 \%$, with Trilete spores and Selaginella sinensis as the dominant type. Moreover, we found a lot of Concentricystes in low plains farmland (Figure 2).

\subsection{Differences in pollen assemblages in farmland among different geomorphic units}

To study the effects of landform on pollen assemblages, the farmland samples were divided into three groups: low plains (28 samples, 0-200 m), hills and high plains (10 samples, $200-500 \mathrm{~m}$ ) and mountains (6 samples, $>500 \mathrm{~m}$ ). The differences in pollen assemblage among the three groups were obvious:

Tree pollen percentage was about $28.5 \%$ in the low plains and was dominated by Pinus (25.9\%), Populus $(0.8 \%)$, Ulmus (0.2\%), Quercus (0.6\%) and Betula (0.6\%). Shrubs were much less common (average $0.3 \%$ ) and were dominated by Rosaceae. Herbs predominated (average $60.6 \%$ ) in the pollen assemblages, especially cereals $(41.6 \%)$, weedy Poaceae $(7.6 \%)$, Chenopodiaceae $(3.6 \%)$ and Compositae (3.0\%). Cyperaceae (1.3\%), Artemisia $(1.3 \%)$ and Typhaceae $(0.9 \%)$ were also common. Trilete spores $(8.2 \%)$ and Selaginella sinensis $(1.8 \%)$ dominated fern spores.

In the hills and high plains, the tree pollen types were similar to those in the low plains, but the overall percent- ages (average $26.5 \%$ ) were slightly lower. Rosaceae was the only shrub type found, with the exception of a single Elaeagnaceae pollen grain recorded at one site, and occurred at much lower percentages (average 0.1\%). Herbaceous pollen types were similar to those in the low plains, but the cereal pollen percentages (average 53.6\%) were distinctly higher than in the low plains or mountains, and the weedy Poaceae percentages (average $4 \%$ ) were also slightly lower than in the low plains. The fern spore percentages (average 5.3\%) were slightly lower than in the low plains, with Trilete spore and Selaginella sinensis decreasing to $4.17 \%$ and $0.6 \%$ respectively.

The tree pollen percentages in the mountains (average $41.7 \%$ ) were distinctly higher than that in the other two landforms. Larix (average 13\%) was only recorded in the mountains, and the percentages of Quercus (average 1.8\%) and Betula (average 2.8\%) were notably higher. However, the percentages of Pinus (23.3) decreased slightly. The herbaceous pollen percentages also declined relative to the other two landforms. Cereals (average 11.2\%) were distinctly more common, whereas weedy Poaceae (average 15.9\%), Compositae (average 7.3\%), Artemisia (average $3.3 \%$ ), Chenopodiaceae (average 4.9\%), Cruciferae (average $1.5 \%$ ), Convolvulaceae (average $2.3 \%$ ), Cucurbitaceae (average $0.3 \%$ ) and Caryophyllaceae (average 0.4\%) were slightly less common. The fern spore percentages (average $5.4 \%$ ) were very similar to those in the hills and high plains, and Selaginella sinensis was very rare.

\subsection{Pollen assemblages in different land-use types}

We demonstrated that different geomorphic units have different pollen assemblages. To better understand the impacts of humans and to determine whether different land use types within the same geomorphic unit had different pollen assemblages, we compared all nine wasteland samples with nearby farmland samples. The sample pairs, as listed in Table 1, were: (DB03, DB04), (DB05, DB06), (DB07, DB08), (DB15, DB16), (DB20, DB21), (DB24, DB25), (DB30, DB31), (DB35, DB36) and (DB37, DB38).

Trees $(25.1 \%)$ and herbs $(63.3 \%)$ dominated the pollen assemblages in the farmlands. Pinus $(23.06 \%)$ was the most abundant tree pollen type; Betula, Populus, Ulmus were also common. Rosaceae $(0.26 \%)$ was the dominant shrub. Herbs were dominated by cereals (49.9\%), with other species recorded with lower percentages such as weedy Poaceae $(5 \%)$, Compositae (2.1\%), Chenopodiaceae (2.5\%) and Artemisia (1.5\%). Most fern spores were Trilete spore $(8.9 \%)$ or of Selaginella sinensis $(2.0 \%)$.

The major pollen types of wasteland were similar to those of farmland, with were present at different percentages. For example, most tree pollen percentages (average $39.4 \%$ ) (e.g. Pinus, Betula, Quercus) were markedly higher

1) Takishi. Nakagawa, 2005. Polation1.0 program, Unpublished. 


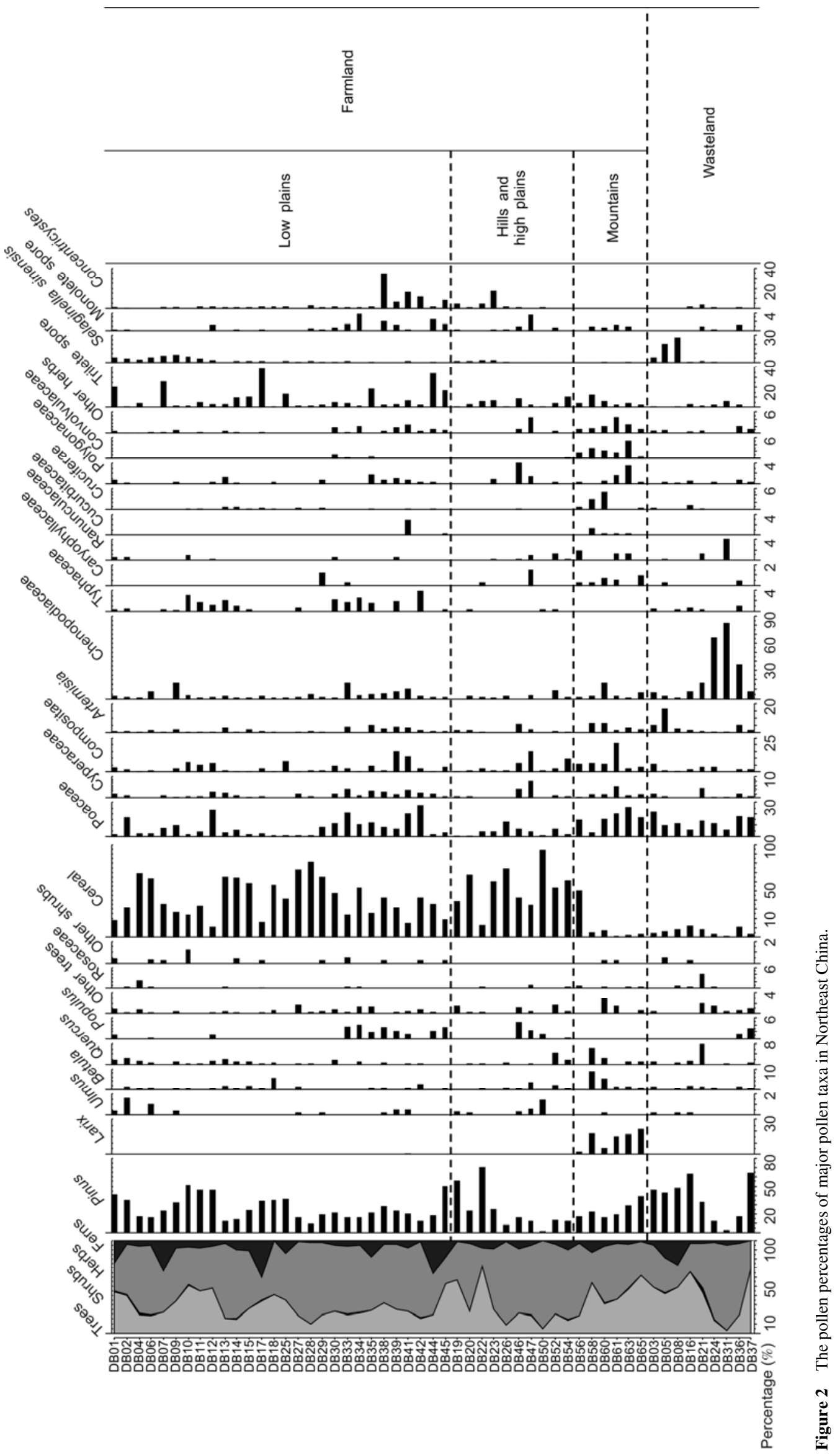


than in the farmlands, although Populus and Ulmus were slightly less common. Herbaceous pollen percentages were distinctly lower, especially for cereals (6\%), although weedy Poaceae (12.4\%), Artemisia (3.7\%), and Chenopodiaceae $(25 \%)$ increased notably (Figure 3 ).

Clustering analysis (CA) of the main pollen types found

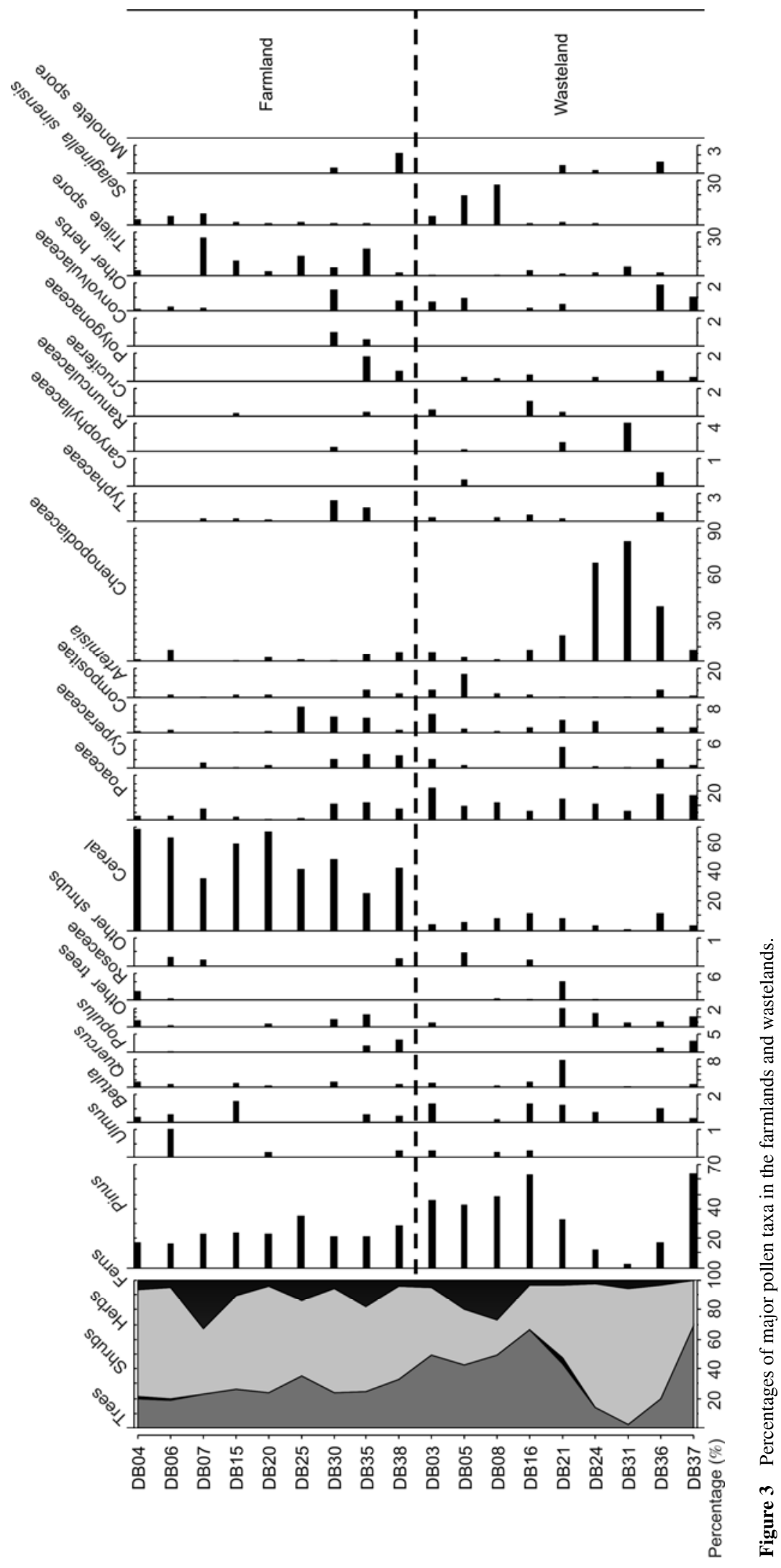


obvious differences in the pollen assemblages of 18 farmlands and wastelands. Samples from the two land use types were clearly divided into distinct groups (Figure 4).

\subsection{PCA and RDA}

(i) PCA. To understand the relationship between climate and pollen assemblages in the human-disturbed vegetation, 22 main pollen types (together making up to $99 \%$ of the pollen) were used for PCA and RDA (Figure 5). The PCA eigenvalues were 0.28 and 0.14 , respectively, for the first and the second principal components, while the third and fourth principal components were 0.12 and 0.09 , respectively.

The ordination results for the main pollen types (Figure 5(a)) showed that Larix, Quercus, Betula and other tree pollen types, as well as some herbaceous taxa such as Compositae, Cyperaceae, Ranunculaceae and Cruciferae, were located in the first quadrant. Pinus, Rosaceae, Chenopodiaceae, and weedy Poaceae, which were all common in wasteland, were scattered in the second quadrant. Cereals, Ulmus, Typhaceae and Selaginella sinensis, which mainly appeared in the low plains, were distributed in the third and the fourth quadrants.

The ordination results for samples are shown in Figure 5(b). Three groups could be identified from the 53 samples. Group 1 included 34 samples, most from the farmlands in the low plains, hills, and high plains, which were mainly distributed in the second and the third quadrants. Group 2 included five samples mainly from farmland in the mountains; all were scattered in the first quadrant. Group 3 included nine samples mainly from wastelands and distributed in the second quadrant. Thus, PCA can differentiate samples from farmland and wasteland and can also distinguish samples from the mountains, plains, or hills. These results are consistent with those of the clustering analysis (Figure 4).

(ii) RDA. To better understand the relationship between climate and pollen assemblages in the human-disturbed vegetation in Northeast China, RDA was used. $T_{\mathrm{a}}$, MAP, and $T_{\mathrm{w}}$ were selected as the main climate parameters, and 22 major pollen types (the same as in the PCA) represented the pollen assemblages. RDA analyses (Table 2) indicated that all three climatic parameters were significantly related to

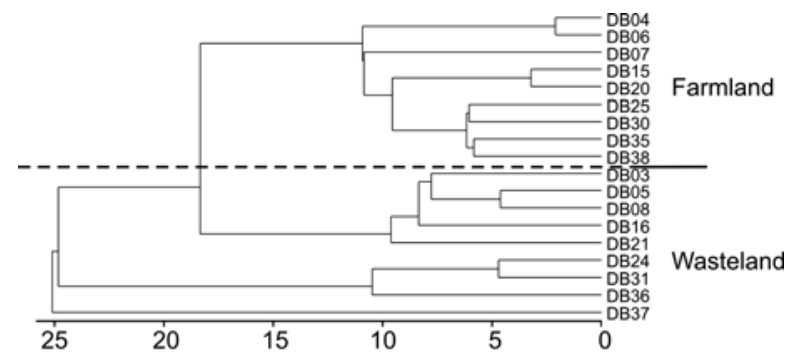

Figure 4 Clustering analysis results for the samples from the farmlands and wastelands. the sample scores in axes 1 and 2 (eigenvalues were 0.45 and 0.18 , respectively).

$T_{\mathrm{a}}$ and $T_{\mathrm{w}}$ were significantly negatively correlated ( $p=$ 0.01 ) with axis 1 , with coefficients -0.73 and -0.81 , respectively. On the contrary, MAP was positively correlated to sample scores in axis $2(r=0.48, p=0.01)$. Therefore, it seems that the pollen assemblages in the study areas were mainly influenced by temperature, then precipitation.

\section{Discussion}

\subsection{Pollen assemblages and vegetation in different geomorphic units}

Farmland pollen assemblages from different geomorphic units were similar. For example, major pollen types were the same, tree pollen usually constituted more than $30 \%$ of the pollen, and cereal usually made up more than $40 \%$. However, there were some differences among the different geomorphic units. For example, the tree pollen percentages (average $41.7 \%$ ) in the mountains were markedly higher than in either the low plains (average $28.5 \%$ ) or the hills and high plains (average 26.5\%). The tree pollen percentages, including Quercus, Betula, and Larix, increased with elevation. Weeds, e.g. weedy Poaceae, Compositae and Artemisia, normally grow better in the understory or in wasteland; the percentages of these pollens were higher in the mountains than in the low plains $(7.6 \%)$ or hills and high plains $(4.0 \%)$. Cereal pollen percentages also differed in different geomorphic units. The cereal pollen percentage was much lower in the mountains than in the other geomorphic units. This is because cereal crops were common in the lower farmlands. Typhaceae pollen was often recorded in rice fields. Populus and Ulmus were only recorded in low plains and hills and high plains, never in the mountains. Populus and Ulmus are common street trees in northern China, which explains the distribution of their pollens in lower areas near populations.

In the study area, the easiest way to convert natural landscapes to farmland is to clear herbs and shrubs first. As a consequence, the tree pollen assemblages represent the natural regional vegetation much better than the assemblages of herbs and shrubs. For example, Larix pollen was only recorded in the mountains, and the percentages of Pinus, Quercus, and Betula, which are usually montane taxa, were higher in the mountains than in the other areas. Ulmus and Populus, which are often planted in the plains, were not recorded or very rare in the mountains, indicating that pollen assemblages are consistent with the regional vegetation composition.

\subsection{Pollen assemblages in different land use types and human impacts}

Herbaceous pollen percentages were higher in the farmlands 

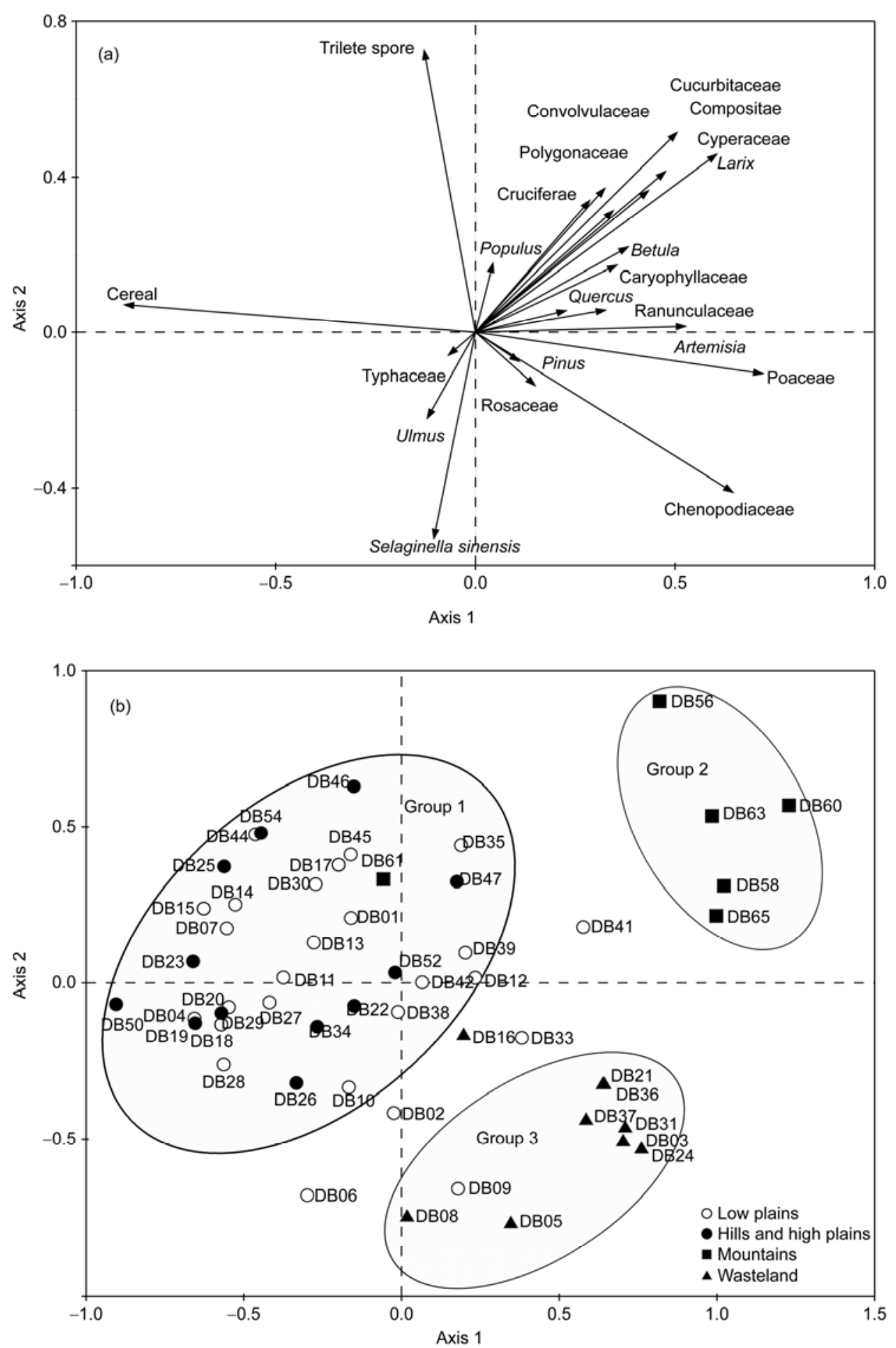

Figure 5 Ordination results of principal component analysis (PCA) for major pollen types (a) and samples (b) in Northeast China.

Table 2 The results of RDA

\begin{tabular}{lcccc}
\hline Parameter & Axis 1 & Axis 2 & Axis 3 & Axis 4 \\
\hline Eigenvalue & 0.45 & 0.18 & 0.03 & 0 \\
$T_{\mathrm{a}}$ & -0.73 & 0.35 & -0.01 & 0 \\
MAP & -0.40 & 0.48 & 0.31 & 0 \\
$T_{\mathrm{w}}$ & -0.81 & 0.03 & -0.02 & 0 \\
\hline
\end{tabular}

than that in the wastelands. Cereal (average 49.9\%, 25.4\%$68.6 \%$ ) was the major pollen type in the farmlands; other herbs types were much rarer. In contrast, the wastelands had many more pollen types, and the pollen percentages of cereal (average $2.5 \%, 0.3 \%-7.6 \%$ ) were much lower. Chenopodiaceae (average $25 \%, 0.86 \%-81.3 \%$ ) in wasteland increased markedly compared with farmland (average $2.5 \%$, 
$0.3 \%-7.6 \%)$. The pollen percentages of Artemisia, Compositae and Cyperaceae were higher than that in the farmlands. During fieldwork, we found more Chenopodiaceae plants growing along the roads and in wasteland, which could explain the higher percentages of this family in the wastelands than in the farmlands. Obviously, humans have seriously influenced farmland vegetation, and the vegetation composition was much less diverse, while the wastelands were less strongly impacted by humans and the vegetation included more taxa in more complicated assemblages.

Surveys of the pollen assemblages of human-disturbed vegetation from Northwestern China [16], the central and southern parts of Northern China and the northern parts of Central China [18], and the subtropical rice areas [15] showed similar patterns. The pollen types in the farmlands were similar to those in the nearby wastelands, but the farmland herbs pollen assemblages were dominated by cereals, while Chenopodiaceae and weedy Poaceae had higher pollen percentages in the wastelands.

Nevertheless, the degree of difference in cereal pollen percentages between wasteland and farmland varied by region. In the subtropical rice areas [15], the average percentage of Oryza-type pollen in rice fields was generally $20 \%$ higher than in dry areas 5-10 m from the rice fields. In the central and southern parts of Northern China and the northern parts of Central China [18], the average cereal pollen percentage in farmland was about $15 \%$ higher than in dry lands. In northwestern China [16], the cereal percentage in the farmlands was $11 \%$ higher than in nearby wasteland. In this paper, the average cereal pollen percentage in the farmlands was $28.35 \%$ higher than the wastelands. There were significant differences in the cereal pollen contents between different land use types in the subtropical rice regions and in Northeast China and lesser differences in the Northwest. The scale of farmland in these areas may explain these results. The barren soil and poor climate (lower temperature and moisture) in Northwestern China are not conducive to crop growth, and the scale of farmland there is less than in other areas. Therefore, the cereal pollen percentages were lower overall in Northwestern China than in eastern China, and the degree of change between farmland and wasteland was consequently less than in eastern China.

In farmland where different types of crops were planted, the pollen assemblages were different. Pollen assemblages in the cereal farmlands were dominated by cereals; weedy Poaceae were still rich in vegetable plots, but the pollen percentages of Cucurbitaceae, Cruciferae, and other common vegetables were higher than in the cereal farmlands (although still less than 5\%). Vegetables such as Daucus carota and Brassica oleracea are usually harvested before blooming, which could explain the lower vegetable pollen percentages [17,32]. Moreover, the pollen productivities of some plants, such as Solanum tuberosum, Lycopersicum esculentum, Capsicum frutescens, Cucurbita pepo and Phaseolus $[32,33]$ are usually lower. Finally, smaller crop fields can also result in lower percentages of vegetable pollens.

In Anyang, middle-south region of Hebei Province, the central and southern parts of Northern China, and the northern parts of Central China, Pollens from some entomophilous plants are only recorded in the farmlands where those plants grow. For example, Malvaceae pollen was only found in the cotton-growing areas [17]; Solanaceae pollen only appeared in tobacco field at less than $1 \%$, in addition, legume pollen was recorded in fields of Arachis hypogaea and Glycine $\max$ at very low percentages [18]. Therefore, to better evaluate historical human impacts, potential crop and vegetable pollens must be carefully assessed. Even very low pollen percentages might still indicate human agricultural activities.

Moreover, total pollen concentrations were also quite different between farmland and wasteland. Concentration averaged 3909 grains/g in the farmlands, far lower than in the wastelands (15074 grains/g average, 87446 grains/g maximum) (Figure 6). This result could be related to the dominant plant pollen productivities as well as the farming methods. In the wastelands, the herbs pollen assemblages were dominated by Chenopodiaceae, which have high pollen productivities $[31,34]$. However, in the farmlands, the pollen assemblages were dominated with Poaceae, which has much lower pollen productivity than Chenopodiaceae [29]. In addition, the artificial removal of weeds by farmers results in fewer herbs (other than crop plants), which also contributes to the lower pollen concentrations in farmland. Finally, different pollen preservation environments could influence pollen concentrations, as well. For example, tillage would enhance surface soil oxidation, and fertilizing and spraying pesticides would change the soil properties; both factors would reduce pollen preservation and decrease surface pollen concentrations [18].

In other areas of China (Table 3), pollen concentrations in wasteland were always higher than in farmland, though patterns varied by crop type and human impact levels. This suggests that human activities are the main cause of low pollen concentrations and that pollen concentration is an important indicator of the intensity of human impacts.

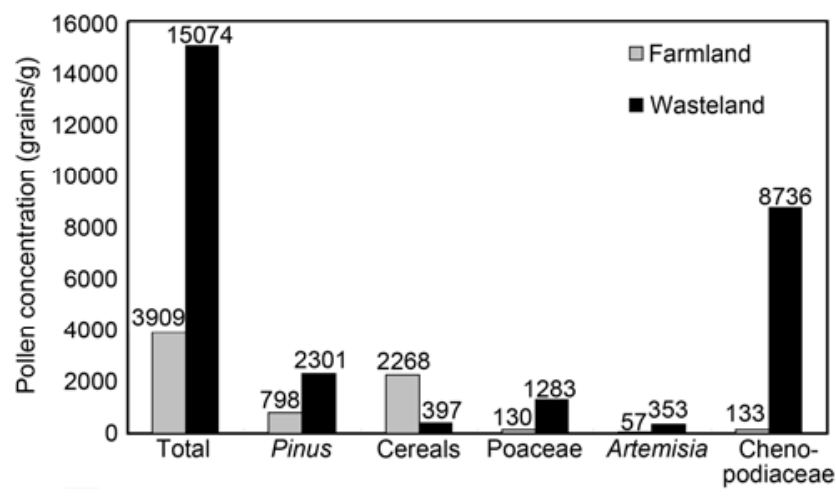

Figure 6 Average pollen concentrations in the farmlands and wastelands. 
Table 3 Pollen concentrations in farmland and wasteland in different areas of China (grains/g) [16-18]

\begin{tabular}{lcccc}
\hline & Northeast China & Hebei Province & Northern China & Southern parts of Northern China and northern Central China \\
\hline Wasteland & 15074 & - & 32704 & 26333 \\
Farmland & 3288 & 3612 & 7227 & 6943 \\
\hline
\end{tabular}

\subsection{Indications of human activities in pollen assemblages of human-disturbed vegetation}

To better understand the influence of human activities on the pollen assemblages of human-disturbed vegetation in Northeast China, we compared our results to those of studies of farmland in Anyang, the middle-south region of $\mathrm{He}$ bei Province, and the central and southern parts of Northern China and the northern parts of Central China (Table 4). We found some common features in the pollen assemblages of different regions of northern China:

(1) In farmland at 0-200 m a.s.1., tree pollen levels were about 30\%, with Pinus the dominant taxon. Herbaceous pollen percentages were usually higher than $50 \%$, with cereals most common at more than $20 \%$. Cruciferae $(0.1 \%-$ $15.5 \%)$, Artemisia (1\%-15.8\%) and weedy Poaceae (5.0\%$7.4 \%$ ) were also quite common.

(2) In farmland at 200-500 m a.s.l., tree pollen percentages were slightly higher than at 0-200 $\mathrm{m}$ a.s.1., while cereal and Cruciferae levels were lower over elevation. Artemisia, Chenopodiaceae and Poaceae became more common over elevation, indicating a decline in human impact.

(3) At elevation 500-1000 m a.s.1., both the tree pollen types and total percentages increased dramatically (more than $40 \%$ on average) and the cereal pollen percentages were usually less than $15 \%$, indicating that natural vegetation was more common and human impact had declined.

There were also some differences in cereal pollen percentages in farmland of different areas. For example, the cereal pollen percentages below $500 \mathrm{~m}$ a.s.l. in Northeast China (more than 40\%) are much higher than in other areas (usually lower than $30 \%$ ). A main cause of this difference is regional climate. The climate is drier and warmer in North China than in Northeast China, so dry farming predominates, and oxidation is stronger in the surface soil. Northeast China is relatively humid and cooler, and oxidation in the surface soil is weaker. These climatological conditions could result in more pollen grains being preserved in Northeast China than in North China and could explain both the higher percentages and concentrations of cereal pollens in the former.

Differences in pollen assemblages might also be caused by the crops planted and the relative areas of cultivation. Maize and wheat are ideal dry-farming crops and are planted across very large geographic scales in Northeast China. In North China [17,33] and Central China [18], the weather is much warmer, permitting more crops, like Gossypium hirsutum and Brassica campestris. The cultivation of other crops will decrease the proportion of cereal grains and affect pollen percentages proportionately. Therefore, pollen assemblages in farmland would be influenced by crop type, planting habits, and tillage techniques. Crop pollen assemblages can reflect farming habits and technology to some degree.

The pollen assemblages of human-disturbed vegetation also differed among the different areas. In Northeast China, cereals and regional tree vegetation (such as Pinus, Betula and Quercus) were abundant in the pollen assemblages. In

Table 4 The differences of pollen percentages in farmland of different altitudes and areas [17,18,33]

\begin{tabular}{|c|c|c|c|c|c|c|c|c|c|c|c|}
\hline & $\begin{array}{l}\text { Altitude } \\
\text { (m) }\end{array}$ & Tree & shrub & Herb & Pinus & Artemisia & Chenopodiaceae & Cruciferae & Cereal & $\begin{array}{c}\text { Weedy } \\
\text { Poaceae }\end{array}$ & $\begin{array}{c}\text { Selaginella } \\
\text { sinensis }\end{array}$ \\
\hline \multirow{3}{*}{ Northeast China } & 0-200 & 28.5 & 0.3 & 60.6 & 25.86 & 1.3 & 3.6 & 0.15 & 41.6 & 7.6 & 1.8 \\
\hline & $200-500$ & 26.5 & 0.1 & 68.0 & 23.5 & 1.3 & 2.0 & 0.02 & 53.6 & 4.0 & 0.6 \\
\hline & $500-1000$ & 41.7 & 0.3 & 52.6 & 23.3 & 3.3 & 5.0 & 1.48 & 11.2 & 15.9 & 0.1 \\
\hline \multirow{3}{*}{ Hebei Province } & $0-200$ & 29.9 & 1.2 & 60.6 & 22.6 & 2.4 & 19.7 & 2.6 & 19.9 & 6.9 & 6.9 \\
\hline & $200-500$ & 48.4 & 1.8 & 38.3 & 36.1 & 3.8 & 5.6 & 0.3 & 18.8 & 4.8 & 11.1 \\
\hline & $500-1000$ & 49.5 & 2.7 & 40.9 & 44.4 & 3.9 & 11.4 & 0.4 & 15.2 & 4.9 & 6.5 \\
\hline \multirow{3}{*}{ Anyang } & $0-200$ & 15.9 & 1.3 & 71.4 & 13.7 & 15.8 & 1.7 & 8.8 & 22.5 & 5.3 & 9.2 \\
\hline & $200-500$ & - & - & - & - & - & - & - & - & - & - \\
\hline & $500-1000$ & - & - & - & - & - & - & - & - & - & - \\
\hline \multirow{3}{*}{$\begin{array}{l}\text { Southern parts of Northern } \\
\text { China and the northern } \\
\text { parts of Central China }\end{array}$} & $0-200$ & 31.6 & 1.0 & 57.4 & 23.2 & 1.0 & 2.5 & 15.5 & 25.0 & 5.0 & 7.0 \\
\hline & $200-500$ & 37.5 & 1.1 & 55.5 & 25.8 & 2.6 & 14.8 & 6.6 & 15.9 & 5.2 & 4.2 \\
\hline & $500-1000$ & 41.7 & 2.8 & 39.5 & 27.9 & 6.2 & 7.4 & 0.4 & 11.4 & 4.5 & 14.6 \\
\hline
\end{tabular}


Hebei Plain, cereals and Chenopodiaceae dominated the pollen assemblages, and the percentages of Selaginella sinensis spores were higher than in other areas. In the Anyang area, the tree pollen percentages were lower than in the other areas and cereals and Cruciferae were the most important herbs, reflecting long and intense human impact. Weeds, such as Artemisia, were also more common than in other areas. In the central and southern parts of Northern China and the northern parts of Central China, cereals, Cruciferae, Chenopodiaceae, Artemisia, and weedy Poaceae were the dominant pollen taxa. Thus, pollen assemblages of human-disturbed vegetation differ due to regional vegetation, crop types, and the degree of human activity.

\subsection{The ecological significance of Concentricystes}

Concentricystes were quite common in the pollen assemblages of farmland in Northeast China (Figure 2). The distribution of Concentricystes shows some regional characteristics: In the plains and hills below $500 \mathrm{~m}$ a.s.l., the Concentricystes content was about $3.4 \%$ on average, with a maximum of $33.7 \%$. Above $500 \mathrm{~m}$ a.s.1., almost no Concentricystes was recorded. Concentricystes are thought to be a freshwater alga with a wide ecological range within humid terrestrial environments. They can also grow in cold freshwaters $[35,36]$. Our samples with the highest percentages of Concentricystes were usually taken near wetland nature reserves and lakes and were probably distributed to the farmlands via irrigation water taken from the lakes and wetlands. Such farmlands are usually wetter than nearby wasteland; seasonally humid environments are suitable for the growth of Concentricystes and may also have contributed to the higher percentages of Concentricystes in some farmlands. Historically, wetlands and marshes were common throughout the plains of Northeast China, so Concentricystes would have been widespread. Many of these wetlands have now been transformed into farmland. Whether Concentricystes were preserved in the surface soil during the transition to farmland should be investigated further.

\subsection{The relationship between pollen assemblages and climate}

Climate is a main factor limiting the distribution of plants, including crops and how they are planted. We found that pollen assemblages of human-disturbed vegetation reflect the influence of climate. In the mountains, climatological factors (especially temperature) limit the distribution of cereals and promote the cultivation of vegetables that can endure cold, both of which were reflected in the increased percentage of vegetable pollens and the dramatically decrease of cereal pollens in the assemblages. Larix and other cold-tolerant plant pollens only appeared at high levels in the mountains. The pollen proportions of some common montane plants, such as Quercus, Betula and Pinus, were also higher than in other areas. On the contrary, plants that prefer warmer climates, such as Ulmus, had higher pollen percentages in the plains than in the colder mountains, and Larix and Betula were very rare or absent in the plains. RDA showed that the pollen assemblages in Northeastern China had significant negative correlations with $T_{\mathrm{a}}$ (mean annual temperature, -0.73 ) and $T_{\mathrm{w}}$ (July mean temperature, -0.81 ) and were also significantly positively correlated with MAP (mean annual precipitation, 0.48). To summarize, the pollen assemblages of human-disturbed vegetation reflect regional climates well.

\section{Conclusions}

Northeast China is located in the forest vegetation zone. The pollen assemblages of human-disturbed vegetation usually contained more than $30 \%$ tree pollen. Moreover, the major taxa in the pollen assemblages were consistent with the vegetation, suggesting that the pollen assemblages of humandisturbed vegetation reflect the regional vegetation composition.

There were differences among pollen assemblages in different geomorphic units. In the mountains, there were more types of tree pollens, at higher percentages, than in other areas. The percentage of cereals was distinctly higher in the plains than in the mountains. The proportions of $P i$ nus and Concentricystes were highest in the low plains. Pollen assemblages were notably different between farmland and nearby wasteland in the same region. Wasteland had many more types of pollen and higher pollen concentrations (average 15074 grains/g, maximum 87446 grains/g) than did farmland. Cereal pollens in wasteland usually made up less than $10 \%$ of the total. On the contrary, in farmland, total pollen levels were much lower (average 3910 grains/g), and fewer pollen types were recorded, but the cereal pollen percentage was $49.9 \%$ on average. PCA and RDA analyses indicated that wasteland and farmland samples could be readily distinguished, as could farmland samples from mountains versus plains. Human activity was probably a major cause of the lower pollen concentrations in farmland, suggesting that pollen concentration is an important indicator of human activities. More attention should be paid to the pollens of vegetables and other crops, even when their percentages are low, in fossil pollen assemblages to recognized historical human activities.

Artificial or human-disturbed vegetation reflects regional climate well. RDA showed that the pollen assemblages in Northeast China were significantly negatively correlated with $T_{\mathrm{a}}$ (mean annual temperature, -0.73 ) and $T_{\mathrm{w}}$ (July mean temperature, -0.81 ) and were significantly positively correlated with MAP (mean annual precipitation, 0.48).

Our study and other investigations of pollen assemblages in northern China demonstrated that the major pollen types and percentages are closely correlated to latitude and altitude. 
The pollen assemblages of human-disturbed vegetation in different areas differed due to the regional vegetation, the types of crops, human impact intensities, and other factors. Cereals and Cruciferae both increased in frequency with declining altitude. Cereals pollen concentrations and percentages in farmland varied with geographic area due to differences in planting habits and climate.

This work was supported by the Key Program of the National Natural Science Foundation of China (40730103), the National Natural Science Foundation of China (41071132) and Hebei Natural Science Foundation (D2008000186 and D2009000300).

1 Sun X W, Xia Z K. Paleoenvironment changes since Mid-Holocene revealed by a palynological sequence from Sihenan Profile in Luoyang, Henan Province (in Chinese). Acta Sci Nat Univ Pekinensis, 2005, 41: 289-294

2 Xu Q H, Li R L, Zhu F, et al. Pollen sedimentary facies of fluvial sediments on North China Plain (in Chinese). J Palaeogeogr, 2001, 3: $55-63$

3 Xu Q H, Xiao J L, Toshio N, et al. Climate changes of Daihai Basin during the past 1500 from a pollen record (in Chinese). Quat Sci, 2004, 24: 341-347

4 Wang X L, Li Y C, Xu Q H, et al. Modern pollen distribution in the middle and north of Luliang Mountains, Shanxi Province. Acta Ecol Sin, 2008, 28: 3682-3690

5 Zhang Y L. Palynological assemblages and palaeovegetation and palaeoclimate of the Holocene in eastern Shanghai (in Chinese). J Palaeogeogr, 2006, 8: 35-41

6 Zhu C, Ma C M, Zhang W Q, et al. Pollen record from Dajiuhu Basin of Shennongjia and environmental changes since $15.753 \mathrm{ka}$ B.P. (in Chinese). Quat Sci, 2006, 26: 814-826

7 Qin D H. Climate and Environment Changes in China (Volume I): Climate and Environment Changes in China and Their Projections (in Chinese). Beijing: Science Press, 2005. 485-506

8 Henan Provincial Institute of Cultural Relics and Archaeology. Jiahu Site in Wuyang (Volume II) (in Chinese). Beijing: Science Press, 1999. 897-903

9 Zhang W X, Yuan J R. A Preliminary Study on the Ancient Rice Excavated from Yuchanyan, Daoxian, Hunan Province (in Chinese). Acta Agro Sin, 1998, 24: 416-420

10 Edwards K J, MacDonald G M. Holocene Palynology II: Human influence and vegetation change. Prog Phys Geogr, 1991.15: 364-391

11 Court-Picon M, Alexandre B, Beaulieu J L. Modern pollen-vegetation relationships in the Champsaur valley (French Alps) and their potential in the interpretation of fossil pollen records of past cultural landscapes. Rev Palaeobot Palynol, 2005, 135: 13-39

12 Court-Picon M, Alexandre B, Beaulieu J L. Modern pollen/vegetation/land-use relationships in mountain environments: An example from the Champsaur valley (French Alps). Veget Hist Archaeobot, 2005, 15: 151-168

13 Buttler A, Mazier F, Galop D. Modern pollen assemblages from grazed vegetation in the western Pyrenees, France: A numerical tool for more precise reconstruction of past cultural landscapes. Holocene, 2006, 16: 91-103

14 Liu H Y. Quaternary Ecology and Global Change (in Chinese). Bei- jing: Science Press, 2002. 108-150

15 Yang S X, Zheng Z, Huang K Y, et al. Surface pollen analysis in subtropical double-cropping rice areas and its archaeological application (in Chinese). Quat Sci, 2010, 30: 262-272

16 Ma Y L, Xu Q H, Huang X Z, et al. Pollen assemblage characters of human disturbed vegetation in arid area in northwestern China (in Chinese). J Palaeogeogr, 2009, 11: 946-956

17 Pang R M, XU Q H, Ding W, et al. Pollen assemblage of farmlands in central and southern Hebei Province (in Chinese). Acta Geogr Sin, 2010, 65: 1345-1354

18 Ding W, Pang R M, Xu Q H, et al. Surface pollen assemblages as indicators of human impact in the warm temperate hilly areas of eastern China. Chin Sci Bull, 2011, 56: 996-1004

19 Zhu H. The Racial Types of Ancient Population in Northeast Region of China (in Chinese). World Antiquity, 1998, 1: 54-64

20 Editorial Committee of Inner Mongolia Forest. Inner Mongolia Forestry (in Chinese). Beijing: China Forestry Press, 1989. 4-372

21 Editorial Committee of Liaoning Forest. Liaoning Forestry (in Chinese). Beijing: China Forestry Press, 1990. 8-10, 50-120

22 Editorial Committee of Jilin Forest. Jilin Forestry (in Chinese). Changchun: Jilin Science and Technology Publishing House, 1988. 16-347

23 Editorial Committee of Heilongjiang Forest. Heilongjiang Forestry (in Chinese). Harbin: Northeast Forestry University Press, 1993. 7-305

24 Team of Investigation of Inner Mongolia and Ningxia, Chinese Academy of Sciences. Vegetation of Inner Mongolia. Beijing: Science Press, 1985. 1-466

25 Faegri K, Iversen J. Textbook of Pollen Analysis. 4th ed. New York: John Wiley \& Sons, 1989. 69-89

26 Andersen S T. Identification of wild grass and cereal pollen. Danmarkes geologiske Undersogelse, Arbog, 1978, 69-92

27 Lan S Y, Xu Z X. Pollen Spin-off Graphic by Scanning Electron Microscope (in Chinese). Beijing: Science Press, 1996. 11-20

28 Xu Q H, Li Y C, Yang X L, et al. Surface pollen assemblages of some major forest types in Northern China (in Chinese). Quat Sci, 2005, 25: 585-597

29 Wang F Y, Song C Q, Sun X J. Study on surface pollen in middle Inner Mongolia, China (in Chinese). Acta Bot Sin, 1996, 38: 902-909

30 Li Y C, Xu Q H, Wang X L, et al. Modern pollen assemblages of the forest communities and their relationships with vegetation and climate in Northern China (in Chinese). Acta Geogr Sin, 2008, 63: 945-957

31 Xu Q H, Li Y C, Yang X L, et al. Study on surface pollen of major steppe communities in northern China (in Chinese). Geogr Res, 2005, 24: 394-402

32 Zhang L Y, Xu Q H, Li Y C, et al. Pollen Influx and Surface Pollen Assemblages in Helan Mountain (in Chinese). Geogr Geo-Info Sci, 2007, 23: 102-106

33 Wang X L, Li Y C, Xu Q H, et al. Pollen assemblages from different agricultural units and their spatial distribution in Anyang area (in Chinese). Chin Sci Bull (Chin Ver), 2010, 55: 544-554

34 Sang Y L, Ma Y Z, Gao S Y, et al. Pollen assemblages and numerical analysis of surface samples from Xinglong Mountain National Reserve, Gansu (in Chinese). Acta Palaeontol Sin, 2008, 47: 457-467

35 Ke M H. Discovery and significance of the Concentricystes fossils on Loess Plateau (in Chinese). Journal of Xi' an Engineering University, 2007, 23: 102-106

36 Zhang Y L, Zhang M B. Discovery of freshwater algae in marine sediments and paleoenvironmental significance (in Chinese). Mar Sci Bull, 2002, 21: 36-40

Open Access This article is distributed under the terms of the Creative Commons Attribution License which permits any use, distribution, and reproduction in any medium, provided the original author(s) and source are credited. 